\title{
Evolving Trends in Teaching: Narration and Imagination vs Video Footages
}

\author{
Urooj Fatima \\ Department of Psychology, Virtual University of Pakistan, \\ Lahore, Pakistan
}

\begin{abstract}
The research discussed in this paper aims to study the impact of video footages on the academic performance of students. Video footages are usually inserted into video lectures - in addition to the verbal narration of any examples by the teachers - to explain and simplify concepts. Similarly, in conventional classrooms, teachers verbally narrate examples to clarify concepts - but, in this case, students have to rely on their imagination and previous exposure to similar situations to develop an understanding of the concepts.
\end{abstract}

A two-phase experiment was designed to compare these two teaching methods. A sample of 70 participants was drawn from non-psychology students in the Virtual University of Pakistan; and two groups, Group A and Group B, each with 35 participants, were formed through random assignment of the students. In the first phase of the experiment, members of Group A were taught through a 24-minute video lecture on psychology, which had four chunks of video footage in it. After the lecture, the students' academic learning was measured through a multiple-choice test with 27 items, which was developed by incorporating an equal number of questions on three levels of Bloom's taxonomy (viz. understanding, comprehension and application). The item levels were decided after agreement by three examiners who had at least three years of experience of developing such questions. In the second phase, a lecture with similar content was taught to Group B. The only difference was in the mode of delivery: in this case, the content was conveyed verbally and no video footages were used. The same test of students' learning was employed to get the scores of Group B. In addition, a qualitative study, involving data gathered through participants' feedback on the performance of the learning facilitators and weaknesses in both teaching modes was collected in order to explore the participants' perceptions and 
experiences of the phenomenon being studied. The results indicated that the two groups were significantly different in terms of academic achievement. The mean values suggested that those who were taught through video footages showed a higher level of academic learning than those who received a traditional verbal narration lecture. In addition, the students reported that the video footages and examples facilitated their learning, and helped them to remain focused and motivated in class. The findings have broad implications for teachers, content developers, academic policy-makers and producers involved in the production of academic content.

Keywords: online learning, video lectures, video footages

\section{Introduction}

Online education systems originated from the roots of traditional distance education in which courses were taught through correspondence (Means, Toyama, Murphy, Bakia, \& Jones, 2010). The emergence of distance and online education with the confluence of technological advances has revolutionized the dynamics of conventional education systems. Online education provides its learners with the facility for asynchronous and real-time communication between instructors and students (Means et al., 2010).

A broad range of teaching techniques embedded in technology are being utilized by online learning education systems to facilitate learning, among which video lectures can be considered an important element (Cognition and Technology Group, 1992). Unlike conventional teaching, video lectures resulted from the combined efforts of many people from diverse backgrounds. Rigorous efforts have been employed to develop the video footage insertions for lectures to make them more lively and understandable for the students. The main driving force which led the researcher to conduct this experimental study stemmed from her experience as a content developer, which required her to become involved in the post-production process at Virtual University Television for graduate level video courses. She therefore became interested in knowing whether or not the virtual exposure of contextual situations through the technology of video footages had any impact on students' academic learning. Video footages are the visual aids of contextual situations and students are shown particular scenarios to which a teacher is referring during a lecture. For instance, a video of a roadside accident is incorporated into a lecture when a teacher gives an example of it. 


\section{Literature Review}

Recently questions about the appropriate use of technology for teaching have been given a great deal of attention (Congress, 1995; Smerdon et al., 2000; Wheeler, Renchler, Conley \& Summerlight, 2000; Zhao, 2003). Although it is very challenging to find cause and effect relationships because teachers, instructional modes and curriculum objectives vary in different cases, experimental research design has attained prominence in educational research (Brown, 1992; Cobb, Confrey, Lehrer, \& Schauble, 2003; Collective, 2003) — and a mainly similar approach was adopted to conduct the present study. Clayton, Blumberg, and Auld (2010) reported that students prefer traditional learning because they consider it matches their personal styles of learning and helps them to remain focused.

Rogers and Coughlan (2013) contend that, with the increasing affordability of technology, video technology has become educators' preferred means for facilitating learning. Traditional classrooms are readily furnished with video-audio stimulations, computers and projectors. However, in online learning, videos are not considered as a replacement for face-to-face interaction but as a valuable learning tool used as a complementary tool in workshops, lectures and seminars (Rogers \& Coughlan, 2013). According to Herron, Hanley, and Cole (1995), video can be used as a creative means for helping students visually contextualize the material that is available in printed format. In virtual learning environments, videos can be employed in addition to practical and theoretical knowledge for reinforcing better understanding of the content (Rogers \& Coughlan, 2013). He (2013) suggested an interesting online learning model by making students interact formally and informally through video communications while studying in an online learning system. He considered video communication among students as a learning facilitator — in his opinion, students will learn formally and informally through such interactions in potential learning environments.

A diverse range of findings have been reported by various researchers in this regard. For example, Salomon (1984) said that learning through television was considered easier by learners than learning from books. Also, stories portrayed in videos, as compared to expository material, help learners to easily understand and recall the lecture content (Peck, Jonassen, \& Wilson, 1999). According to Chaiklin and Lave (1996), the best learning environments entail the engaged experiences with real-world scenarios where social relationships are in action and the learner can easily identify with them. With reference to the present study, it is worth mentioning here that video technology use has its roots in socio-cultural learning theories 
that highlight the effective role of real-world contexts in enhanced learning (Merriam, Caffarella, \& Baumgartner, 2012). On the other hand, the Cognition and Technology Group (1992) considered video technology as an interesting way to teach which has the potential to convey complicated ideas in a simple and understandable way.

Literature on the efficacy of video lectures takes into account its attribute of involving visual and auditory systems (Baggett, 1984). Baggett found that learning is memorable if attained visually; and many researchers support the same idea that simultaneous visual and audio processing of information supports the learning process and makes it more memorable and understandable for learners (Kozma, 1991; Overbaugh, 1996). A review of the literature on learning and motivation reveals that motivation has a potential role to play in academic learning and achievement (Ames, 1990). Research has shown that instructional material has a strong impact on students' motivation level (Hidi \& Harackiewicz, 2000); and motivated learners tend to involve themselves in the learning of challenging tasks and experience pleasure from their academic achievements (Stipek, 1993). Videos are an effective means to make content interesting (Cognition and Technology Group, 1992), and hence help to motivate students to learn. However, according to Mitra et al. (2010), videos become most effective if used as a part of a blended learning approach. The Virtual University of Pakistan has adopted a blended approach to learning, and along with video lectures, included graded discussion boards; moderate discussion boards, assignments, quizzes and e-mail correspondence. Video lectures encompass slides, audio and video simulations but lack real-time face-to-face tutoring. The focus of the present research is on studying the effects of video footages on the academic learning of the students.

\section{Methodology}

\section{Sample and procedures}

The total sample consisted of 70 non-psychology faculty members of the Virtual University of Pakistan, of whom 42 were female and 28 male, with an age range of 23 to 36 years. Two groups - Group A and Group B, with 35 students in each group - were formed. However, the experiment was done in two sessions, initially with 30 participants (15 in each group) and then 40 more (20 in each group) took part in this study. To control the non-treatment variables, such as gender and prior experience, the groups were formed through random assignment, which helps to ensure the probabilistic equitability of experimental groups on all known and unidentified variables at the pre-experimental stage (Mitchell \& Jolley, 
2012).

In the first phase of the experiment, those in Group A were taught through a 24-minute video lecture on psychology which had four chunks of video footage in it. After the delivery of the content to participants, their learning was measured through multiple-choice questions with 27 items, equally divided among three levels of Bloom's taxonomy. Half of the test items were based on content delivered in the video footages.

Item levels were decided after the mutual agreement of three examiners with at least three years of experience of developing questions according to Bloom's taxonomy. For determining inter-rater reliability, Cohen's kappa statistic was used, and items were revised until perfect agreement among the raters was achieved.

In the second phase, similar content was taught to Group B. The only difference was the mode of delivery as it was conveyed verbally, with no video footages used. The same test was employed as in Group A to get Group B's scores.

In order to explore the phenomenon in depth, a qualitative study was also carried out. For this purpose, after taking the test, participants were asked to list the strengths of the lecture which helped them to learn and retain the information while attempting the test. Feedback about the weaknesses of the lecture or the aspects students found difficult to learn and retain was also collected.

\section{Hypothesis}

It is expected that Group A (taught with the help of video footages) will perform better on an academic learning test compared to Group B (taught through conventional classroom mode without visual aids).

For the qualitative study, the following research question was formulated:

- What are the experiences and perceptions of the participants about both modes of teaching?

\section{Results}

An independent samples $t$ test was performed to compare the academic achievement of Group A - who were taught through a video lecture with video footages in addition to verbal examples - and Group B who were 
taught through the conventional classroom mode through verbal narrations of examples, without any visual aids. In Group B, the participants had to rely on their imagination skills to remember, understand and recall the lecture content. The inter-rater reliability for the evaluators rating the three levels of test items according to Bloom's taxonomy was found to be kappa = 0.96 ( $\mathrm{p}<.0 .001), 95 \%$ CI $(0.809,1.117)$. According to the guidelines given

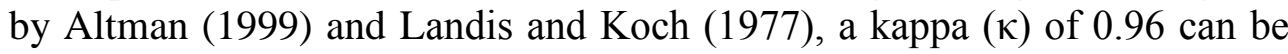
interpreted as 'almost perfect agreement'.

Levene's test was found to be assuming equal variances for the present analysis, $\mathrm{F}(1.68)=2.3, \mathrm{p}=.13$. Owing to this, a $t$ statistic assuming homogeneity of variance was computed. As predicted, Group A, which was taught with the help of video footages $(M=23.20, S D=3.0, N=35)$ performed better on the MCQ test than the Group B $(M=17.20, S D=4.07$, $N=35), t(68)=7.08, p<.05$, two-tailed).

Table 1 Means, standard deviations and t-value of the academic learning of Group A and Group B

\begin{tabular}{lllll}
\hline Groups & $N$ & $M$ & $S D$ & $T$ \\
\hline Video footages & 35 & 23.20 & 3.0 & \\
Verbal narration & 35 & 17.20 & 4.07 & 7.08 \\
\hline
\end{tabular}

$\mathrm{df}=68 . * \mathrm{p}<.05$

These results suggest that inserting video footages into video lectures does have an impact on students' learning and academic achievement. Thus the proposed hypothesis was supported by these results.

\section{Qualitative Analysis}

The content analysis of the data collected for qualitative exploration was carried out by using the principles of a grounded theory approach (Straus \& Corbin, 1998). The major categories which emerged also supported the results obtained through statistical analysis. Initially, more than 100 codes emerged, forming two major categories: learning facilitator attributes of the lecture and difficulties in retaining information. 
Table 2 Major categories and a few examples of sub-categories which emerged

\begin{tabular}{|c|c|c|}
\hline \multicolumn{2}{|r|}{$\begin{array}{c}\text { Emerged major } \\
\text { categories }\end{array}$} & Examples of sub-categories \\
\hline 1 & $\begin{array}{l}\text { Learning facilitator } \\
\text { attributes of the } \\
\text { lecture }\end{array}$ & $\begin{array}{l}\text { - } \text { Video footages enhanced learning. } \\
\text { - } \text { Interesting examples } \\
\text { - Videos helped to remain focused. } \\
\text { - } \text { Videos cause interest. } \\
\text { - } \text { understand concepts. } \\
\text { Content of videos easy to recall while } \\
\text { attempting the test } \\
\text { - The smiling face of the teacher } \\
\text { Teacher having good communication } \\
\text { skills. }\end{array}$ \\
\hline 2 & $\begin{array}{l}\text { Lecture } \\
\text { weaknesses } \\
\text { causing difficulty } \\
\text { in information } \\
\text { retention }\end{array}$ & $\begin{array}{l}\text { - Absence of visual aids } \\
\text { - } \text { Graphs and charts would have made it } \\
\text { - } \text { Mony to understand. } \\
\text { - } \text { Boring } \\
\text { - } \text { Difficulty to focus } \\
\text { - Unknown concepts }\end{array}$ \\
\hline
\end{tabular}

Interestingly, both the major categories which emerged indicated the positive and the learning facilitating role of visual aids (see Figure 1). Participants in Group B identified the lack of visual aids as a weakness of the lecture, whereas Group A acknowledged the supportive role of video footages for their learning. The participants in Group A considered the video footages not only as one of the major reasons for helping them to understand the concepts, but also mentioned them as a supportive aspect for examinations. They considered it easier to remember the concepts which were explained with the help of video footages while taking the test. 


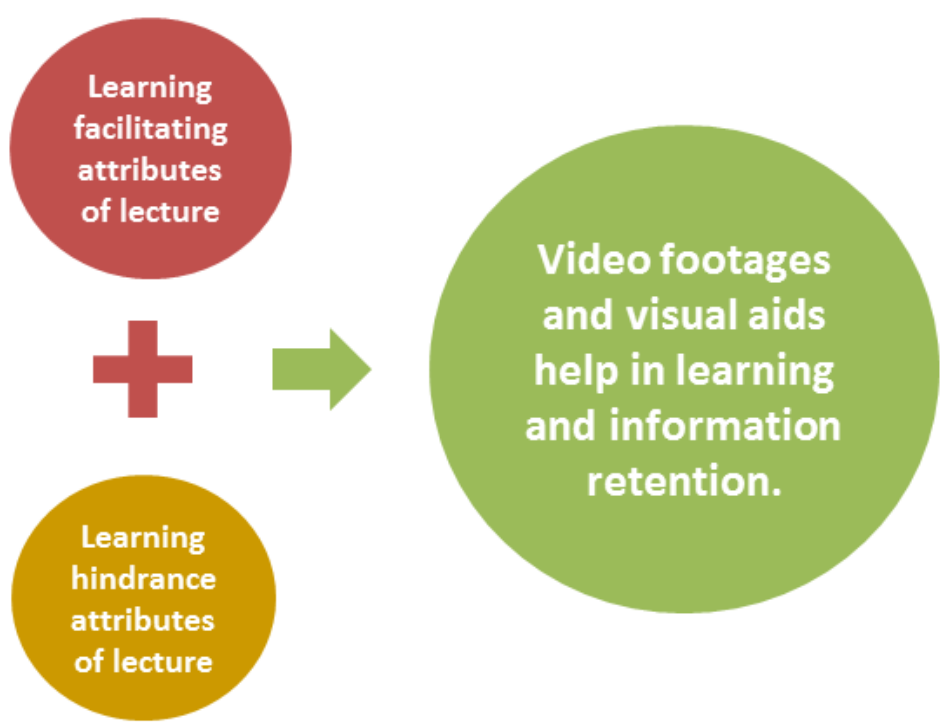

Figure 1 Video footages as a learning enhancer

Once the major categories were determined, the frequencies of each category were calculated. It was found that 33 out of the 35 participants (94\%) in Group A considered video footages as a learning facilitator which helped them to learn and retain the information. One participant commented that 'video in the lecture helped me to remain focused on the lecture' and another said that, because of videos, lecture became interesting and understandable for him.

On the other hand, 31 out of $35(88 \%)$ in Group B pointed out the absence of some visual aids (e.g. slides and graphs) as a weakness of the lecture. For example, a participant remarked that 'graphs would have made it easier for me to understand the information'. This made it boring and monotonous, as noted by 29 out of $35(83 \%)$ in Group B.

However, both groups considered daily-life examples (both verbal and video footages) as learning facilitators that helped them to understand the concepts and then attempt the test.

\section{Discussion and Conclusion}

The results of this experimental study indicate that video footages enhance students' academic learning, and contextual visualization of examples helps them to attain a richer understanding of the information. Content analysis of participants' feedback about learning facilitators and learning 'halters' also supported the results obtained through statistical analysis of the scores 
obtained. Participants considered video footages as learning facilitators which helped them to retain and recall information and maintain interest in the lecture. They reported that they enjoy the learning because of visual aids. The results are in alignment with various previous studies (Kozma, 1991; Overbaugh, 1996).

The findings of the present study have implications not only for online learning environments. Conventional and all other modes of teaching should also incorporate visual aids to make learning an enjoyable, fruitful and rich experience for students. Nonetheless, the present study was limited in scale and future studies may incorporate a larger sample size.

\section{References}

Altman, D. G. (1999). Practical statistics for medical research. New York, NY: Chapman \& Hall/CRC Press.

Ames, C. A. (1990). Motivation: What teachers need to know. Teacher College Record, 91(3), 409-421.

Baggett, P. (1984). Role of temporal overlap of visual and auditory material in forming dual media associations. Journal of Educational Psychology, $76(3), 408-417$.

Brown, A. L. (1992). Design experiments: Theoretical and methodological challenges in creating complex interventions in classroom settings. The Journal of the Learning Sciences, 2(2), 141-178.

Chaiklin, S., \& Lave, J. (1996). Understanding practice: Perspectives on activity and context: Cambridge University Press.

Clayton, K., Blumberg, F., \& Auld, D. P. (2010). The relationship between motivation, learning strategies and choice of environment whether traditional or including an online component. British Journal of Educational Technology, 41(3), 349-364.

Cobb, P., Confrey, J., Lehrer, R., \& Schauble, L. (2003). Design experiments in educational research. Educational Researcher, 32(1), 9-13. 
Cognition and Technology Group. (1992). An anchored instruction approach to cognitive skills acquisition and intelligent tutoring. In Cognitive approaches to automated instruction, ed. J. W. Regian and V. J. Shute, 135-170. Hillsdale, NJ: Lawrence Erlbaum Associates, Inc.

Collective, T. D.-B. R. (2003). Design-based research: An emerging paradigm for educational inquiry. Educational Researcher, 5-8.

Congress, U. (1995). Office of Technology Assessment (1995). Teachers and technology: Making the connection. Washington, DC: Government Printing Office. IX et.

He, W. (2013). Examining students' online interaction in a live video streaming environment using data mining and text mining. Computers in Human Behavior, 29(1), 90-102.

Herron, C. A., Hanley, J. E., \& Cole, S. P. (1995). A comparison study of two advance organizers for introducing beginning foreign language students to video. The Modern Language Journal, 79(3), 387-395.

Hidi, S., \& Harackiewicz, J. M. (2000). Motivating the academically unmotivated: A critical issue for the 21st century. Review of Educational Research, 70(2), 151-179.

Kozma, R. B. (1991). Learning with media. Review of Educational Research, 61(2), 179-211.

Landis, J. R., Koch, G. G. (1977). The measurement of observer agreement for categorical data. Biometrics 33:159-174

Means, B., Toyama, Y., Murphy, R., Bakia, M., \& Jones, K. (2010). Evaluation of evidence-based practices in online learning: A meta-analysis and review of online learning studies.

Merriam, S. B., Caffarella, R. S., \& Baumgartner, L. M. (2012). Learning in adulthood: A comprehensive guide. John Wiley \& Sons

Mitchell, M., \& Jolley, J. (2012). Research design explained. Cengage Learning.

Mitra, B., Lewin-Jones, J., Barrett, H., \& Williamson, S. (2010). The use of video to enable deep learning. Research in Post-Compulsory Education, 15(4), 405-414. 
Overbaugh, R. C. (1996). The efficacy of interactive video for teaching basic classroom management skills to pre-service teachers. Computers in Human Behavior, 11(3), 511-527.

Peck, K., Jonassen, D., \& Wilson, B. (1999). Learning with technology: A constructivist perspective. Upper Saddle River, NJ: Merrill.

Rogers, D., \& Coughlan, P. (2013). Digital video as a pedagogical resource in doctoral education. International Journal of Research \& Method in Education, 36(3), 295-308.

Salomon, G. (1984). Television is 'easy' and print is 'tough': The differential investment of mental effort in learning as a function of perceptions and attributions. Journal of Educational Psychology, 76(4), 647.

Smerdon, B., Cronen, S., Lanahan, L., Anderson, J., Iannotti, N., \& Angeles, J. (2000). Teachers' Tools. National Center for Education Statistics, 2(4), 48 .

Stipek, D. J. (1993). Motivation to learn: From theory to practice.

Strauss, A., \& Corbin, J. (1998). Basics of qualitative research: Techniques and procedures for developing grounded theory (2nd ed.). Thousand Oaks, CA: Sage.

Wheeler, M., Renchler, R., Conley, K., \& Summerlight, S. (2000). National educational technology standards for students: Connecting curriculum and technology: ERIC.

Zhao, Y. (2003). What should teachers know about technology? Perspectives and Practices, 2, 1. 